\title{
Correlation between Serum Calcium Levels and Smear Grading Among the Pulmonary Tuberculosis Patients
}

\author{
T. Jaya Chandra ${ }^{1}$, M. Sowjanya ${ }^{2}$ \\ ${ }^{1}$ Department of Microbiology, GSL Medical College, Rajahmundry, Andhra Pradesh, India \\ ${ }^{2}$ Department of Biochesmitry, Adikavinannaya University, Rajahmundry, Andhra Pradesh, India
}

\begin{abstract}
Objective: To find the serum calcium (Ca) levels in the pulmonary tuberculosis (PT) patients and its correlation with smear grading.

Methods: Microscopically confirmed PT patients were included in the test group and healthy individuals in the control group. Two sputum samples were collected from the participants by the same day approach. Smears were stained by Ziehl Neelsen staining technique. Simultaneously $5 \mathrm{ml}$ blood was collected; serum was separated by centrifugation at 3000 rpm, 10 minutes. Serum Ca was estimated by kit method, by auto analyzer. ANOVA test was used to find the statistical significance.
\end{abstract}

Results: Total 100 participants were included. The mean serum Ca levels were $7.2 \mathrm{mg} / \mathrm{dL}$ and $9.4 \mathrm{mg} / \mathrm{dL}$ in the test and control groups, respectively. Grade wise the mean serum Ca levels were $7.4 \mathrm{mg} / \mathrm{dL}, 7.3 \mathrm{mg} / \mathrm{dL}, 7.1 \mathrm{mg} / \mathrm{dL}$ and 7 $\mathrm{mg} / \mathrm{dL}$ respectively for scanty, $1+.2+$ and $3+$. Statistically the difference was not significant among the groups and the grades.

Conclusion: As per our study hypocalcemia is observed in PT patients and the mean serum Ca levels were decreased with smear grading. J Microbiol Infect Dis 2018; 8(1):19-22

Keywords: Calcium, levels, mean, serum

\section{INTRODUCTION}

Mycobacterium tuberculosis (MTB) complex, an acid fast bacillus (AFB) is the causative agent of tuberculosis (TB). Nearly $90 \%$ of cases occur in low- and middle-income (LMI) countries [1]. India is the highest TB burden country in the world [2, 3], $26 \%$ of total TB cases [4].

MTB can infect any organ in our body [5]. But lung infection, pulmonary tuberculosis (PT) is common. Inhalation of aerosols produced by the infected person is the main route of transmission of PT. People with low living standards and poverty are the contributory factors for the spread of PT [5]. Further, PT also causes lung damage as well as death, if not treated properly [6].

In LMI, high TB burden countries such as India, Pakistan and most sub-Saharan Africa, rapid TB diagnostic tests are not possible due to their high cost. Hence, sputum microscopy is therefore the only feasible diagnostic tool for TB in these settings [79]. For sputum microscopy, two sputum samples are collected. Most of the national TB control programs insist on spot morning (SM) approach [10] of sputum collection. But, the world health organization (WHO) recommended for switching to same day (SS2) approach [5]. Several scientists reported that the diagnostic accuracy of the SS2 approach is at par with the SM approach [10-12] and Ziehl Neelsen (ZN) staining is commonly used microscopy technique for the diagnosis of PT.

In India, due to high population as well as TB burden, significant number of people may get exposed to MTB. But, due to immunity, all MTB exposed individuals don't get TB. For optimum immunity, nutrition plays an important role. If the intake of nutrients is hampered, leads to

Correspondence: Dr T. Jaya Chandra, Department of Microbiology, GSL Medical College, Rajahmundry, Andhra Pradesh, India E-mail: chanduthegreat2014@gmail.com 
deficiency and the individual prone for infections. In this regard, minerals also play an important role [14]. But, the normal homeostatis mechanism regulates level of calcium (Ca) [15].

Several investigators studied on level of serum (Ca) among the TB patients [16-19]. But, we cannot find studies on correlation between levels of serum $\mathrm{Ca}$ and smear grading.

With this, a study was undertaken to find the serum $\mathrm{Ca}$ levels and its correlation with smear grading among the PT individuals.

\section{METHODS}

This was a case control study, conducted in the department of Microbiology, GSL Medical College, Rajahmundry, Andhra Pradesh, South India. Study protocol was approved by the institutional ethics committee. An informed consent was collected from all the participants.

Study consisted of test and control groups. Newly diagnosed PT patients were included in the test group; individuals who are on anti TB treatment (ATT), previously treated cases, dropouts and defaulters were not included. Healthy individuals were considered in the control group; these are the employees of this institution who don't have patient exposure.

Two sputum samples were collected from the participants by the SS2 approach; that is 2 sputum samples were collected with a gap of one hour. Smears were prepared and stained by ZN staining technique. Collection of sputum samples, smear preparation, staining, screening under microscope was done as per the RNTCP guidelines [20].

From the participants, $5 \mathrm{ml}$ of blood was collected; serum was separated by centrifugation at $3000 \mathrm{rpm}, 10$ minutes. Serum $\mathrm{Ca}$ was estimated by kit method, by auto analyzer. ANOVA test was used to find the statistical significance between the groups and also between the grades. $\mathrm{P}$ value of less than 0.05 was considered for statistical significance.

\section{Smear preparation}

A new unscratched slide was selected for smear preparation. Smear was prepared with sterile loop. A good smear is spread evenly, over a size of $2 \times 3 \mathrm{~cm}$ and is neither too thick nor too thin. This was allowed to air dry for $15-30 \mathrm{~min}$ and fixed by passing it over a blue flame $3-4$ times [20].

\section{ZN Staining}

Smears, flooded with filtered $1 \%$ carbol fuchsin (CF) were heated until it was steaming and left to steam for $5 \mathrm{~min}$. After rinsing the slides with a gentle stream of water, $25 \%$ sulphuric acid was used to decolorize the smears for $2-4$ min and if necessary decolorization step may be repeated for another $1-3 \mathrm{~min}$. The slides were rinsed as above and counterstained with $0.1 \%$ methylene blue for 30 seconds. The slides were then washed, air dried and examined under oil immersion [20].

\section{Grading of Smear}

The smears were graded using $100 \mathrm{X}$ oil immersion objective as per the RNTCP technical manual [20].

\section{RESULTS}

Total 100 participants were included in the study; test and control groups were studied at the ratio of 1 i.e. 50 participants in each group. Among the smear positive (SP) cases, the male female ratio was 1.42 and mean age was 41.2 years. The mean serum $\mathrm{Ca}$ levels were 7.2 $\mathrm{mg} / \mathrm{dL}$ and $9.4 \mathrm{mg} / \mathrm{dL}$ in the test and control groups, respectively; statistically the difference was not significant between the groups $(\mathrm{P}>$ 0.05).

Table 1: Smear grading and mean serum calcium in test group

\begin{tabular}{|l|c|c|c|c|c|c|}
\hline Variables & \multicolumn{3}{|c|}{ Gender } & \multicolumn{3}{c|}{ Serum Calcium in mg/dL } \\
\hline Smear grading & Male & Female & Total n (\%) & Male & Female & Mean \\
\hline Scanty & 8 & 6 & $14(28)$ & 7.6 & 7.3 & 7.4 \\
\hline $1+$ & 11 & 6 & $17(34)$ & 7.3 & 7.25 & 7.3 \\
\hline $2+$ & 5 & 3 & $8(16)$ & 7.2 & 7.1 & 7.1 \\
\hline $3+$ & 5 & 6 & $11(22)$ & 7 & 6.9 & 7 \\
\hline
\end{tabular}


In the test group, 28\% (14), 34\% (17), 16\% (8) and $22 \%$ (11) participants were graded as scanty, $1+.2+$ and 3+, respectively. Grade wise mean serum $\mathrm{Ca}$ levels were $7.4 \mathrm{mg} / \mathrm{dL}, 7.3$ $\mathrm{mg} / \mathrm{dL}, 7.1 \mathrm{mg} / \mathrm{dL}$ and $7 \mathrm{mg} / \mathrm{dL}$ for scanty, $1+$. $2+$ and $3+$, respectively; statistically the difference was not significant between the grades $(P>0.05)$ (Table 1$)$.

\section{DISCUSSION}

TB is a disease seen among the poor people with low living standards [5]. The prevalence of TB was reported to be more in male compared to female [21]. In this study also, among the SP cases, the male female ratio was 1.42. Due to simplicity, ease of technique, in the current study, ZN staining was considered for the identification of AFB in sputum smears.

It is well known that alteration of serum $\mathrm{Ca}$ levels in various infections [16]. In one study from India, hypocalcemia was reported by the investigators, the mean serum $\mathrm{Ca}$ levels were $9.3 \pm 0.46 \mathrm{mg} / \mathrm{dL}, \quad 7.72 \pm 1.02 \mathrm{mg} / \mathrm{dL}$, respectively in the smear negative (SN) and $\mathrm{SP}$ individuals [17]. Whereas hypercalcemia was reported by Sharma et al. in another study from India [16]. But the investigators mentioned that hypercalcemia was reported in just $15.5 \%$ TB patients and the mechanism was reported to be unclear. In the current study, newly diagnosed PT patients before initiation of ATT were included in the test group, the mean serum $\mathrm{Ca}$ was $7.2 \mathrm{mg} / \mathrm{dL}$. In the control group, all were healthy individuals; never had TB and SN for AFB. In the control group, the mean serum $\mathrm{Ca}$ level was $9.4 \mathrm{mg} / \mathrm{dL}$. In this study, hypocalcemia was observed among the SP cases and statistically the difference was not significant between the groups $(P>0.05)$.

Grade wise, the mean serum Ca levels were 7.4 $\mathrm{mg} / \mathrm{dL}, 7.3 \mathrm{mg} / \mathrm{dL}, 7.1 \mathrm{mg} / \mathrm{dL}$ and $7 \mathrm{mg} / \mathrm{dL}$ respectively for scanty, $1+2+$ and $3+$ (Table 1$)$; statistically the difference were not significant $(P$ $>0.05$ ) between the grades. These data shows that serum $\mathrm{Ca}$ levels were decreased with increase in the concentration of $A F B$ in the sputum. None of the SP participants were malnourished. As a part of study protocol, when the research team asked, all of them answered that they regularly take $\mathrm{Ca}$ rich foods such as gingelly, milk etc. It was also reported in the literature that in the PT patients, with ATT, the serum Ca levels were turned to normal $[18,19]$. With this information it is clear that MTB is the only cause for hypocalemia.

With this study finding, we conclude that hypocalemia is seen among the PT patients and serum $\mathrm{Ca}$ levels were decreased with increase in the concentration of AFB. Hence regular serum $\mathrm{Ca}$ evaluation and supplementary $\mathrm{Ca}$ therapy is given to the PT patients. However studies on large sample size under field conditions is recommended.

\section{ACKNOWLEDGMENTS}

Conflict of interest: The authors declare no personal or financial conflict of interest.

Acknowledgment: The authors acknowledge the authorities of Adikavi Nannaya University for permitting M. Sowjanya to undertake this work as part of her M.Sc. dissertations.

\section{REFERENCES}

1. World Health Organization. Annual report on Global tuberculosis control: epidemiology, strategy, financing. Geneva: WHO, 2009.

2. Sachdeva KS, Ashok K, Dewan P, Ajay K, Satyanarayana S. New Vision for Revised National Tuberculosis Control Programme (RNTCP): Universal access-"Reaching the un reached. Ind Med Res 2012; 135: 690 - 694.

3. Sitanshu SK, Archana Ramalingam. Same day sputum microscopy: The road ahead in tuberculosis diagnosis. Lung India 2013; 30: 226 227.

4. World Health Organization. Global tuberculosis report, 2014. WHO/HTM/TB/2014.08. Geneva, Switzerland: WHO, 2014.

5. Chandra TJ. Phd Thesis. Saveetha University; 1 December, 2016.

6. Rich A, Thomos C. The pathogenesis of Tuberculosis. 1951;1028.

7. Chandra TJ. Same day sputum smear microscopy approach for the diagnosis of pulmonary tuberculosis in a microscopy center at Rajahmundry. Ind J Tuberc 2012; 59: 141-144.

8. Angeby KA, Alvarado GC, Pineda GL, Hoffner SE. Improved sputum microscopy for a more sensitive diagnosis of pulmonary tuberculosis. Int $\mathrm{J}$ Tuberc Lung Dis 2000; 4: $684-687$.

9. Steingart KR, Vivienne $N G$, Megan $H$, et al. Sputum processing methods to improve the sensitivity of smear microscopy for tuberculosis: a systematic review. Lancet Infect Dis 2006; 6: 664674. 
10. Chandra TJ, Selvaraj R, Ramesh AR, Sharma YV. Same day sputum smear microscopy for the diagnosis of pulmonary tuberculosis: modified ZN staining versus LED FM. Int J Curr Microbiol App Sci 2015; 4: $75-81$.

11. Chandra TJ, Raj RS, Sharma YV. Same day sputum smear microscopy for the diagnosis of pulmonary tuberculosis: direct versus concentrated sputum smear. Int $\mathrm{J}$ Tuberc Lung Dis 2015; 20: $247-251$.

12. Chandra TJ, Raj RS, Sharma YV. Same day sputum smear microscopy approach with modified $\mathrm{ZN}$ staining for the diagnosis of pulmonary tuberculosis in a microscopy centre at Rajahmundry. Ind J Med Microbiol 2014; 32: 153 156.

13. Chandra TJ, Selvaraj R, Sharma YV. Same day sputum smear microscopy for the diagnosis of pulmonary tuberculosis: Ziehl-Neelsen versus fluorescent staining. J Family Med Prim Care 2015; 4: $525-528$.

14. Patil YJ, Caffrey Mc. Tuberculosis Freeman complication of medicine. 2003; 16: $519-523$.

15. Un Sil J. Kidney and Calcium Homeostasis. Electrolyte and Blood Press 2008; 6: 68 - 76.

16. Subhash C Sharma. Serum calcium in pulmonary tuberculosis. Postgraduate Medical Journal 1981; 57: $694-696$.

17. Rohini K, Surekha Bhat, Srikumar PS, Mahesh Kumar A. Assessment of Serum Calcium and Phosphorus in Pulmonary Tuberculosis Patients Before, During and After Chemotherapy. Ind J Clin Biochem 2014; 29.

18. Abbasi AA, Chemplavil JK, Farah S, Muller BF, Arnstein AR. Hypercalcemia in active pulmonary tuberculosis. Ann Intern Med.1979; 90: 324 - 328.

19. Kitrou MP, Phytou-Pallikari A, Tzannes SE, Virvidakis K, Mountokalakis TD. Hypercalcemia in active pulmonary tuberculosis. Ann Intern Med. 1982; 96: 255.

20. RNTCP Central TB Division, Directorate General of Health Services. Manual for Laboratory Technicians. New Delhi, India: Directorate General of Health Services, Ministry of Health and Family Welfare; 1998.

21. Yap B, Atwine D, Orikiriza P, et al. Male Gender is independently associated with pulmonary tuberculosis among sputum and non sputum producers people with presumptive tuberculosis in Southwestern Uganda. BMC Infect Dis 2014; 14: $638-645$. 